Final Report (April 2004)

\title{
The Influence of Calcium Carbonate Grain Coatings on Contaminant Reactivity in Vadose Zone Sediments (DOE Grant FG07-99ER15024)
}

\section{Principal Investigator:}

Prof. Gordon E. Brown, Jr.

Stanford University

Stanford, CA 94305

(650) 723-9168 (phone)

(650) 725-2199 (fax)

gordon@pangea.stanford.edu

\section{Co-Principal Investigators:}

Dr. Scott Chambers

Pacific Northwest National laboratory

P. O. Box 999, MISN K8-93

Richland, WA 99352

(509) 376-1766 (phone)

(509) 376-5106 (fax)

sa.chambers@pnl.gov

Prof. Carrick M. Eggleston

University of Wyoming

P.O. Box 3006

Laramie, WY 82071

(307) 766-6769 (phone)

(307) 766-6679 (fax)

carrick@uwyo.edu

Dr. John M. Zachara

Pacific Northwest National Laboratory

P.O. Box 999, MSIN K8-96

Richland, WA 99352

(509) 376-3254 (phone)

(509) 376-3650 (fax)

john.zachara@pnl.gov

\section{Co-Investigators:}

Dr. Tom Kendelewicz, Stanford University

\section{Graduate Student:}

Colin S. Doyle, Stanford University 


\section{Research Objectives}

This project investigated the role of calcium carbonate grain coatings on the reactivity of several key Hanford zone contaminants such as ${ }^{60} \mathrm{Co}^{2+},{ }^{90} \mathrm{Sr}^{2+},\left[{ }^{99} \mathrm{TcO}_{4}\right],\left[\mathrm{CrO}_{4}\right]^{2-}$. Calcium carbonate in the Hanford subsurface is thought to play an important role in the fate of contaminant species released at the Hanford site. Calcium carbonate can play two conflicting roles in the subsurface: (1) it may enhance uptake of certain contaminants such as ${ }^{60} \mathrm{Co}$ and ${ }^{90} \mathrm{Sr}$, and/or (2) it may impede reductive immobilization of $\mathrm{CrO}_{4}{ }^{2-}$ and ${ }^{99} \mathrm{TcO}_{4}{ }^{-}$by $\mathrm{Fe}^{2+}$ present in vadose zone minerals such as magnetite, ilmenite and biotite by forming a barrier preventing electron transfer, and thus passivating the surfaces of vadose zone minerals. Seasonal cycles of saturation and dessication within the Hanford vadose zone lead to precipitation of calcium carbonate. In the subsurface calcium carbonate is present as grain coatings, intergrain fill, and as distinct caliche layers; it is a minor but ubiquitous component of the Hanford and Ringold formations which make up $85 \%$ of the Hanford vadose zone. Typically vadose zone porewater is in equilibrium (i.e., saturated) with calcium carbonate, and calcium carbonate may precipitate in the subsurface when high-level waste interacts with porewater.

This project involves fundamental research into all aspects of calcium carbonate coating formation and reactivity, with particular attention to the influence of calcium carbonate grain coatings on the reductive immobilization of chromate. In the final year of this study we extended our investigation to the interaction of aqueous chromate with pyrite surfaces, because of the potential for reduction of $\mathrm{Cr}(\mathrm{VI})$ to $\mathrm{Cr}(\mathrm{III})$ on pyrite $\left(\mathrm{FeS}_{2}\right)$ which is the most abundant metal sulfide in most sediments.

\section{Research Findings and Implications}

This report summarizes the results of research conducted at Stanford University (influence of $\mathrm{CaCO}_{3}$ grain coatings on the reduction of $\mathrm{Cr}(\mathrm{VI})$ by magnetite and biotite), which was part of the overall EMSP project. The studies performed at Pacific Northwestern National Laboratory (reactivity of natural $\mathrm{CaCO}_{3}$ in Hanford sediments), and the University of Wyoming (growth and dissolution processes of calcite and magnesite in presence of contaminants) are beyond the scope of this report. 
The formation of calcium carbonate coatings on single crystal magnetite surfaces has been investigated in order to understand how it modifies the reactivity of mineral phases with respect to aqueous chromate. We have performed these experiments using single crystal magnetite (111) surfaces as a model system for Fe(II)-containing Hanford vadose zone minerals, which include magnetite, ilmenite, and biotite. We believe that this model is an accurate reflection of the interaction between aqueous oxoanions such ac $\mathrm{CrO}_{4}{ }^{2-}$ and $\mathrm{TcO}_{4}{ }^{-}$ and Fe(II)-bearing minerals such as magnetite, biotite and ilmenite in the Hanford vadose zone. The coating formation and reactivity has been studied using a combination of synchrotron based X-ray Absorption Near Edge Structure (XANES) and photoemission (PES) along with laboratory based XRD and SEM.

We investigated three routes to produce calcium carbonate coatings on single crystal magnetite (111) surfaces. The first method involved UHV deposition of calcium, followed by oxidation to $\mathrm{CaO}$ with $\mathrm{O}_{2}$, and subsequent $\mathrm{CO}_{2}$ dosing to produce calcium carbonate films. This method, despite initial promise, resulted in a discontinuous film and was not pursued. The second method involved growth of calcium carbonate from solution, while the third allowed calcium carbonate films to build up following repeated dosing and evaporation of calcium carbonate saturated solutions. The results of the solution and evaporation grown coatings will be discussed in turn.

\section{Growth of Calcium Carbonate from Solution}

Calcium carbonate crystals were grown directly on the magnetite surface from aqueous solution by bubbling $\mathrm{CO}_{2}$ through mixtures of $\mathrm{CaCl}_{2}$ and $\mathrm{NaHCO}_{3}$ solutions.

Coating growth was allowed to proceed under these conditions for between one and two hours, and resulted in coatings formed of aggregations of crystallites exhibiting calcite morphology as shown in Figure 1. This morphology differs from that observed in the Hanford subsurface. XRD analysis confirmed calcite as the predominant form of calcium carbonate in the coating. An assessment of film thickness was made by attenuation of the Fe

$2 p$ photoemission signal, and from relative intensities of $\mathrm{Fe}$ and $\mathrm{Ca} L_{\mathrm{II}}, L_{\mathrm{III}}$-edge XANES spectra.

These calcium carbonate films were reacted with $\left[\mathrm{CrO}_{4}\right]^{2-}$ at $\mathrm{pH} 6$, in solutions which were both saturated and unsaturated with calcium carbonate. Dosing of coatings with 
unsaturated solutions resulted in coating dissolution and $\mathrm{Cr}(\mathrm{VI})$ reduction. With saturated solutions, coatings grown for one hour showed $\operatorname{Cr} 2 p$ photoemission, whilst coatings grown for two hours did not. However Cr(III) was observed by XANES for both growth times, with a much weaker signal from the two hour coatings. Photoemission and XANES results are shown in Figure 2.

Significant coating degradation was observed following dosing. Degradation was more pronounced for carbonate unsaturated solutions, and typically resulted in a decreased coverage of calcite rhombs on the magnetite surface.

The presence of $\mathrm{Cr}$ (III) on all coatings grown in this manner and the changes in coating integrity following dosing indicate two significant points, 1) that the degree of calcium carbonate saturation in contaminant containing groundwater is of great importance for the ultimate fate of oxoanion contaminants such as $\mathrm{CrO}_{4}{ }^{2-}$ and $\mathrm{TcO}_{4}{ }^{-}$, and 2) coatings formed through a solution precipitation method may not act as the best models for carbonate coatings in the Hanford subsurface due to their differing structure. These results do however show that calcium carbonate coatings do inhibit the reduction of chromate at the magnetite/water interface.

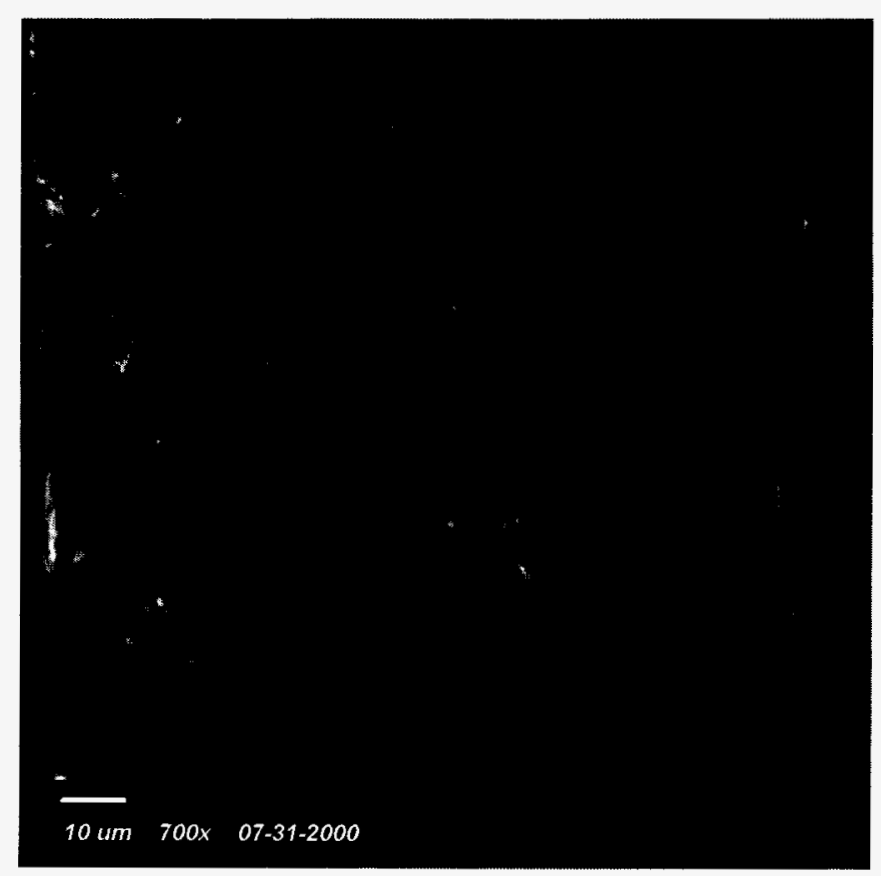

Figure 1: SEM micrograph of a calcium carbonate coating grown for two hours on magnetite(111). XRD analysis confirms that the coating consists of calcite. 

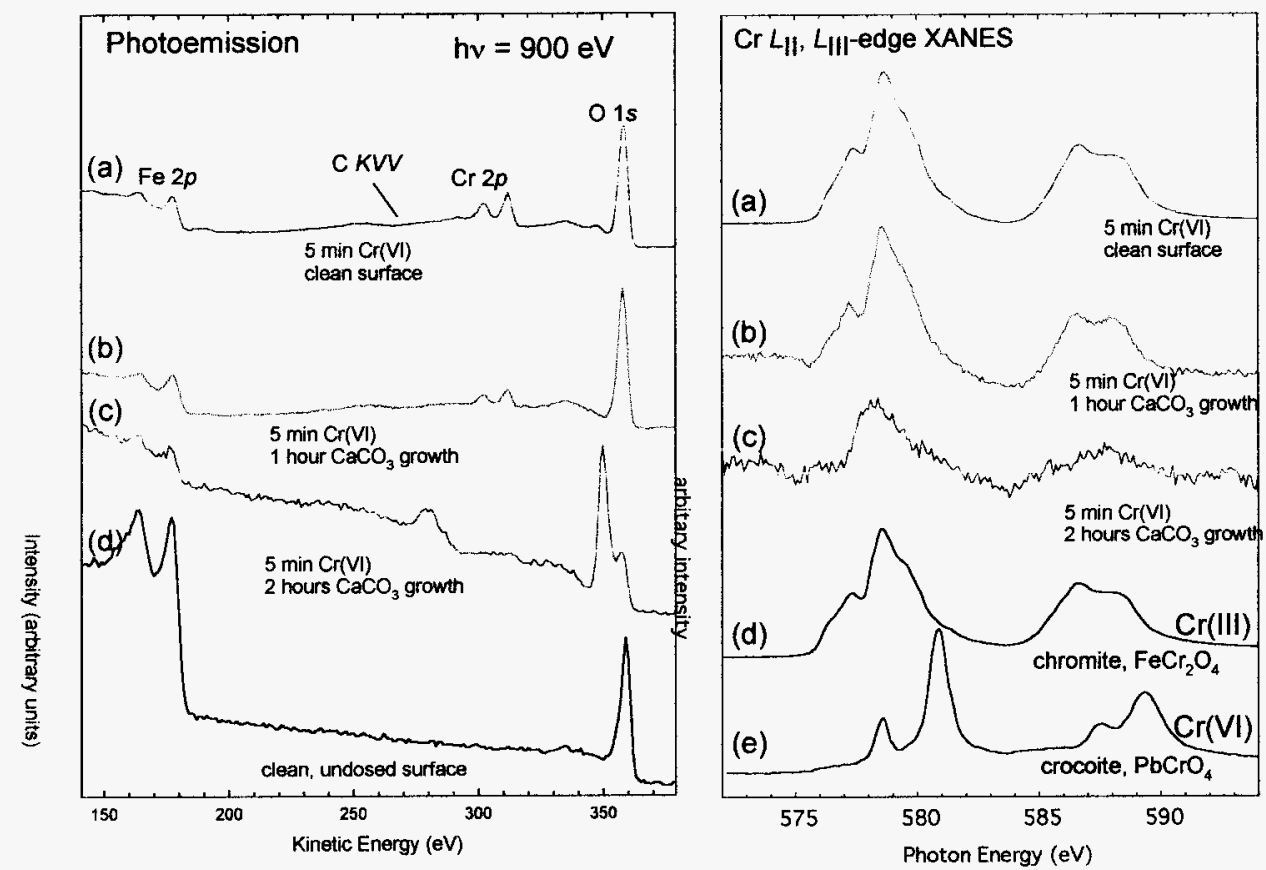

Figure 2: Photoemission (left panel) and $\operatorname{Cr} L_{\mathrm{II}}, L_{\mathrm{III}}$-edge XANES (right panel) spectra showing surface composition and $\mathrm{Cr}$ speciation following $\mathrm{Cr}(\mathrm{VI})$ dosing for (a) uncoated surfaces, (b) surfaces coated for one hour, (c) surfaces coated for two hours. For comparison, PES of a clean, uncoated, undosed magnetite (111), and XANES of representative (d) $\mathrm{Cr}$ (III) and (e) $\mathrm{Cr}$ (VI) compounds are also shown.

\section{Growth of Calcium Carbonate by Evaporation}

We developed a method which closely mimics the processes occurring in the vadose zone at Hanford where seasonal periods of saturation and unsaturation exist, leading to carbonate grain coatings and intergrain fill. This method involved the gradual buildup of a coating by repeated evaporation of a saturated calcium carbonate solution on the magnetite surface. Evaporation of calcium carbonate coatings were performed ex-situ to out UHV analysis system. This resulted in a complete and closed calcium carbonate overlayer as shown in Figure 3, which XRD and $\mathrm{Ca} L_{\mathrm{II}}, L_{\mathrm{III}}$-edge XANES (Figure 4) showed to be primarily of calcite with some vaterite and aragonite.

These calcium carbonate films were shown to impede the reduction of $\left[\mathrm{CrO}_{4}\right]^{2-}$ at the magnetite-water interface. Dosing experiments at $\mathrm{pH} 6$ have been performed using chromate solutions that are saturated with respect to calcium carbonate. Survey photoemission spectra, 
as shown in Figure 5 shows photoemission scans of chromate dose magnetite surface with and without evaporated calcium carbonate coatings. For uncoated surfaces, reduced $\mathrm{Cr}$ (III) is present on the magnetite surface. When coated surfaces are dosed with $50 \mu \mathrm{M}$ chromate, no chromium species is observed on the surface, whereas following dosing with $50 \mathrm{mM}$ chromate solution, unreduced chromate is observed. All coatings grown via this method show complete attenuation of the surface-sensitive $\mathrm{Fe} 2 p$ photopeak by the calcium carbonate overlayer, corresponding to a minimum coating thickness of approximately 10-20 $\AA$, however it is clear from SEM examination that the coatings thickness is in the micron range. This apparent discrepancy is understood in terms of the large crystallite size observed in SEM investigations with a thinner cementing layer, built up over several evaporative cycles, which at it's minimum is on the order of the surface sensitive photoemission attenuation depth. Chromate solutions that are saturated with respect to calcium carbonate showed no reaction with evaporated coatings, or with the underlying magnetite surface. Unreduced sodium chromate was present on the calcium carbonate surface following dosing with $50 \mathrm{mM}$ chromate solution. This unreduced chromate remained following evaporation of the dosing solution, and was readily washed from the coating surface.

The oxidation state of chromium when present on the surface was monitored by $\mathrm{Cr}$ $L_{\mathrm{Il}}, L_{\mathrm{III}}$-edge XANES and Cr $2 p$ photoemission. Figure 6 shows Cr XANES from coated and uncoated evaporation-grown systems following 5 minute doses with sodium chromate solutions, which show that calcium carbonate coatings do retard the reductive immobilization of $\mathrm{Cr}(\mathrm{VI})$, and analogously, $\mathrm{Tc}(\mathrm{VII})$ at the magnetite/solution interface.

These findings indicate that in environments such as Hanford, where significant calcium carbonate formation occurs, that $\mathrm{Cr}(\mathrm{VI})$ and $\mathrm{Tc}(\mathrm{VII})$ should not be completely reduced because of coatings on $\mathrm{Fe}$ (II)-containing mineral grains such as magnetite, ilmenite and biotite. This provides a possible explanation for the recent findings of chromate as the dominant chromium species under the SX-108 tank [1]. 


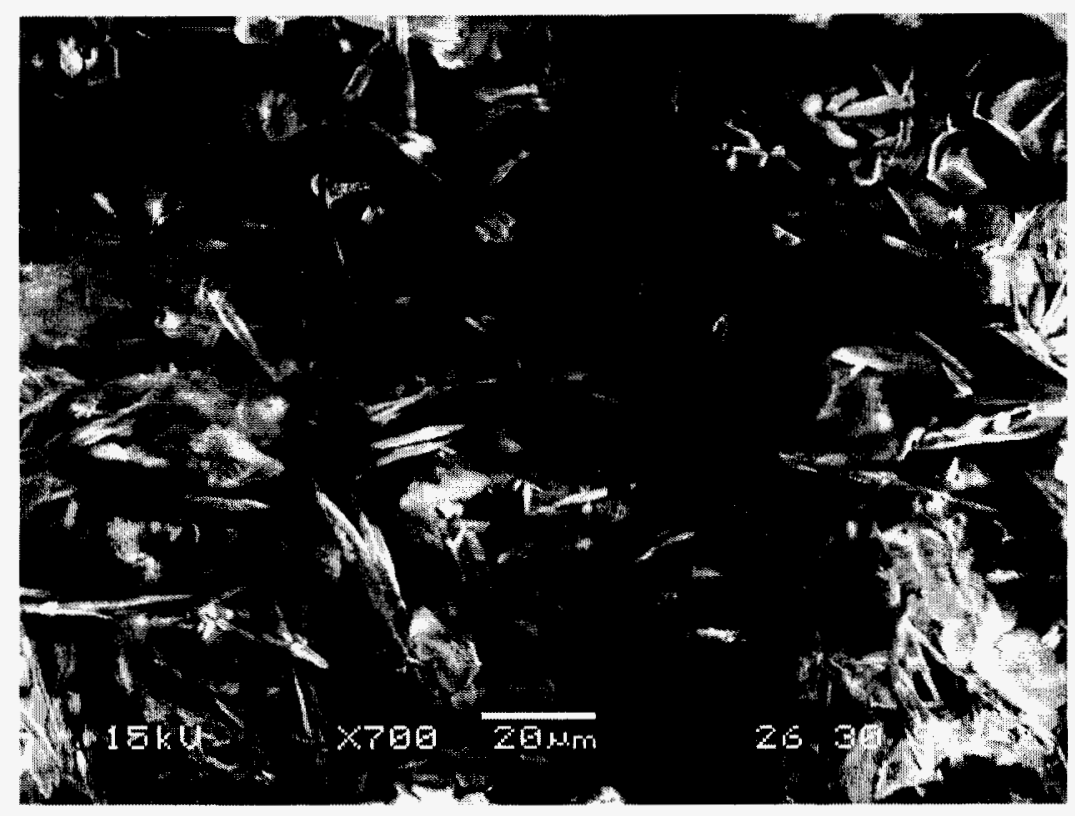

Figure 3: SEM micrograph of calcium carbonate film formed by repeated evaporation of supersaturated calcium carbonate solutions on the magnetite (111) surface.

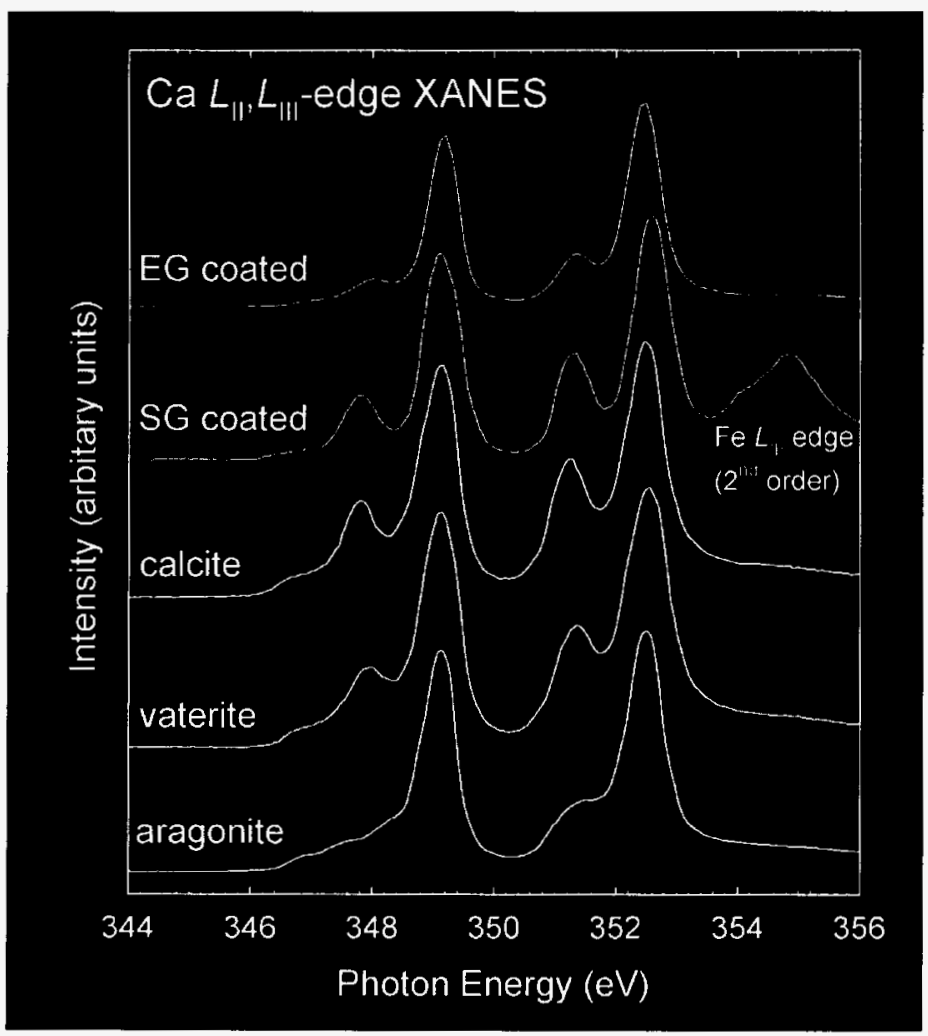

Figure 4: Ca LII,LIII-edge XANES spectra of carbonate coatings grown on magnetite(111), and of the calcium carbonate polymorphs calcite, vaterite, and aragonite; EG refers to coatings formed through the evaporation method, SG refers to coatings grown from solution. 


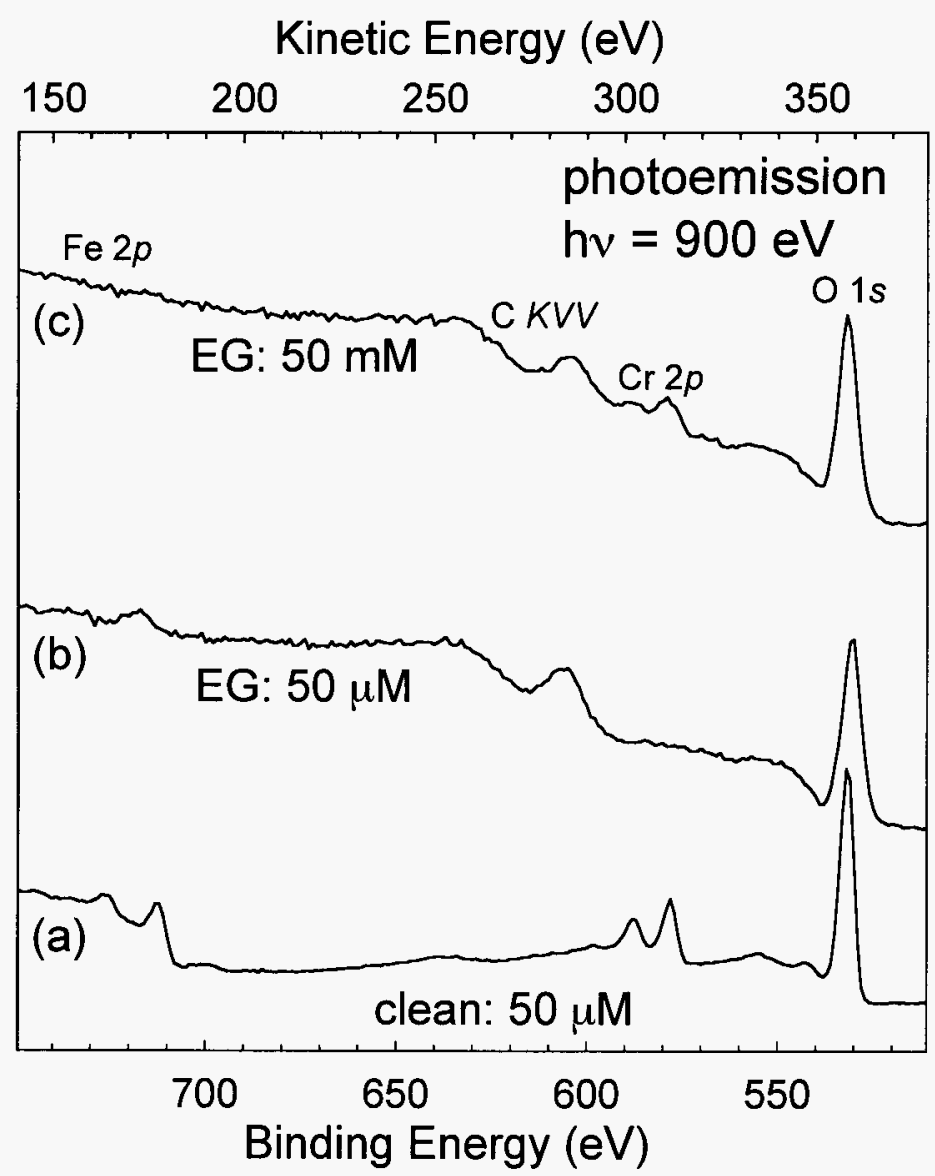

Figure 5: Surface sensitive photoemission spectra for (a) uncoated, and (b,c) coated magnetite surfaces dosed with $\mathrm{Cr}$ (VI). (a) In the absence of a carbonate coating, chromium is reduced to $\mathrm{Cr}$ (III) and binds to the magnetite surface. (b) No chromium species is present following dosing with $50 \mu \mathrm{M} \operatorname{Cr}(V I)$ solution. (c) Unreduced $\operatorname{Cr}(\mathrm{VI})$, but no $\mathrm{Cr}(\mathrm{III})$ is present on the calcium carbonate surface following dosing with $50 \mathrm{mM}$ solution. 


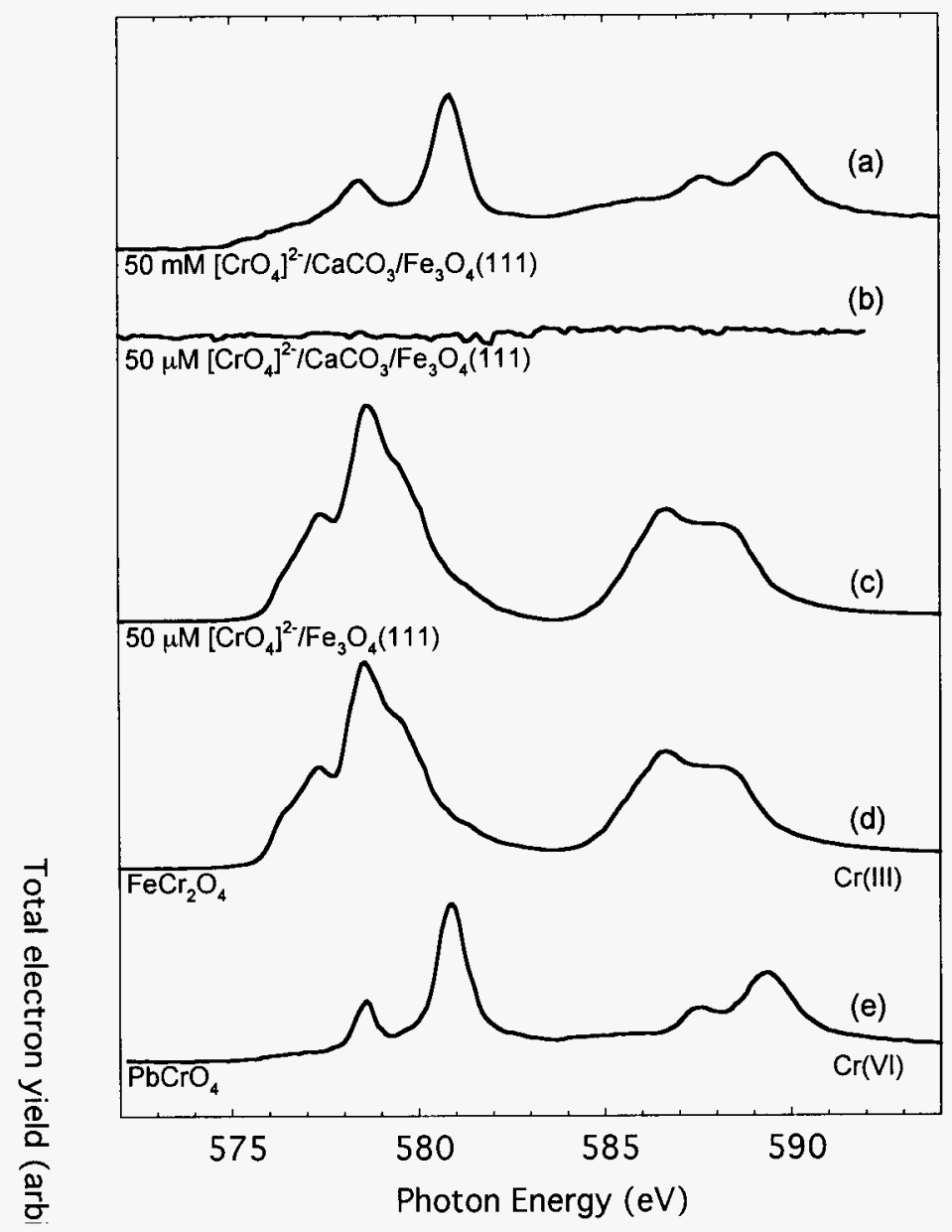

Figure 6: $\operatorname{Cr} L_{11,1 I}-$ edge XANES spectra for coated $(a, b)$ and uncoated (c) magnetite surfaces dosed with $\mathrm{Cr}(\mathrm{VI})$. Unreduced $\mathrm{Cr}(\mathrm{VI})$, but no $\mathrm{Cr}$ (III) is present on the calcium carbonate surface following dosing with $50 \mathrm{mM}$ solution (a). The second and third spectra compare $50 \mu \mathrm{M}$ chromate doses for coated (b) and uncoated (c) surfaces. Reference spectra for $\mathrm{Cr}$ (III) and $\mathrm{Cr}(\mathrm{IV})$, (d) and (e), are also shown. It should be noted that the $\mathrm{Cr}(\mathrm{VI})$ present in (a) is in the form of solid sodium chromate, which is highly soluble and thus mobile. 


\section{Reduction of chromate on pyrite surfaces}

We have used synchrotron based soft x-ray core-level photoemission and adsorption spectroscopies to study the reaction of aqueous sodium chromate solutions with freshly fractured pyrite surfaces. The study has two complementary goals: (1) to investigate the oxidation of pyrite surfaces and identify reaction intermediates, and (2) to assess pyrite as a potential material for the reductive removal and immobilization of hexavalent chromium from solution. Pyrite surfaces were reacted with $50 \mu \mathrm{M}$ sodium chromate solution at $\mathrm{pH} 7$ for reaction times between one minute and thirty-seven hours. Additional experiments were performed at $\mathrm{pH} 2$ and $\mathrm{pH} 4$ with $50 \mu \mathrm{M}$ sodium chromate solutions, and at $\mathrm{pH} 7$ with $5 \mathrm{mM}$ solutions. At chromate concentrations of $50 \mu \mathrm{M}$, all chromate present on the pyrite surface was in the form of $\mathrm{Cr}(\mathrm{III})$, while at $5 \mathrm{mM}$, both $\mathrm{Cr}(\mathrm{III})$ and $\mathrm{Cr}(\mathrm{VI})$ were present at the pyrite surface (Figure 7). Minor quantities of oxidized sulfur species (sulfate, sulfite, and zerovalent sulfur) were identified as reaction products on the pyrite surface. The amount of oxidized sulfur species observed on the surface was greater when pyrite was reacted with $5 \mathrm{mM} \mathrm{Cr}(\mathrm{VI})$ solutions because the rate of chromium deposition exceeded the rate of dissolution of pyrite oxidation products, effectively trapping $\mathrm{Cr}(\mathrm{VI})$ and oxidized sulfur species in an overlayer of iron(III)-containing $\mathrm{Cr}(\mathrm{III})$ hydroxide.

This work shows how pyrite, an extremely cheap and readily available waste material, may be suitable for the removal of hexavalent chromium from acidic to circumneutral waste streams. The reduced chromium forms a coating on the pyrite surface, which passivates the pyrite surface towards further oxidation. 


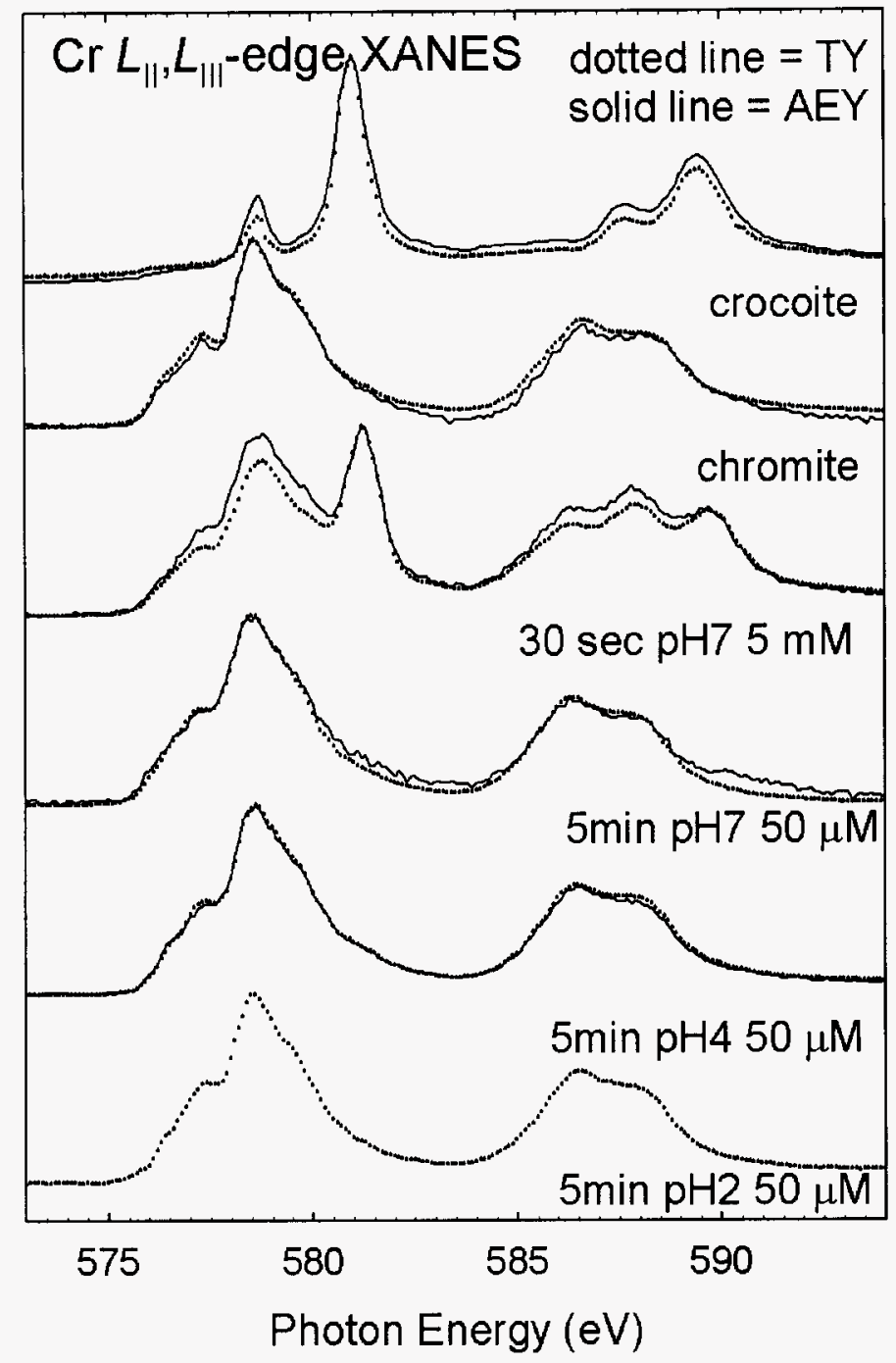

Figure 7: Chromium $L_{\mathrm{II}}, L_{\mathrm{III}}$-edge XANES showing the speciation of chromium at the pyrite surface after 5 minutes reacting with $50 \mu \mathrm{M} C \mathrm{Cr}(\mathrm{VI})$ solution at $\mathrm{pH} \mathrm{2,} \mathrm{pH} 4$ and $\mathrm{pH} 7$, and 30 seconds with 5 $\mathrm{mM} \mathrm{Cr}(\mathrm{VI})$ at $\mathrm{pH}$ 7. The minerals crocoite $\left(\mathrm{PbCrO}_{4}\right)$ and chromite $\left(\mathrm{FeCr}_{2} \mathrm{O}_{4}\right)$ are included as model spectra for tetrahedral $\mathrm{Cr}$ (VI) and octahedral $\mathrm{Cr}$ (III) respectively. Solid lines indicate Auger electron yield data, and broken lines are total electron yield data. 


\section{References}

[1] J.M. Zachara, C.C. Ainsworth, G.E. Brown, Jr., J.G. Catalano, J.P. McKinley, O. Oafoku, S.C. Smith, J.E. Szecsody, S.J. Traina, J.A. Warner, Geochim. Cosmochim. Acta 68 (2004) 13.

\section{Information Access}

\section{Poster/Oral Presentations}

Colin S. Doyle, Tom Kendelewicz, Gordon E. Brown, Jr., Scott A. Chambers, John M. Zachara (2000) The Effect of Calcium Carbonate Coatings on $\mathrm{Cr}(\mathrm{VI})$ Reduction at the (111) Surface of Magnetite. Poster Presentation, Goldschmidt 2000, September $3^{\text {rd }}-8^{\text {th }}, 2000$, Oxford, UK.

Colin S. Doyle, Tom Kendelewicz, Gordon E. Brown, Jr., Scott A. Chambers, John M. Zachara (2000) The Effect of Calcium Carbonate Coatings on Cr(VI) Reduction at the (111) Surface of Magnetite. Poster Presentation, $28^{\text {th }}$ Annual Stanford Synchrotron Radiation Laboratory Users Meeting, October $18^{\text {th }}-21^{\text {st }}, 2000$, SLAC, Menlo Park, CA.

John M. Zachara, Scott A. Chambers, Gordon E. Brown, Jr., and Carrick M. Eggleston (2000) The Influence of Calcium Carbonate Coatings on Contaminant Reactivity in Vadose Zone Sediments. FY2001 EMSP Vadose Zone principal Investigation Workshop, November $28^{\text {th }}-30^{\text {th }}$. W.R. Wiley Environmental Molecular Sciences Laboratory, Pacific Northwest National Laboratory, Richland, WA.

Colin S. Doyle, Tom Kendelewicz, Benjamin C. Bostick, Gordon E. Brown, Jr. (2002) Synchrotron Spectroscopic Studies of the Reaction of Cleaved Pyrite $\left(\mathrm{FeS}_{2}\right)$ Surfaces with Cr(VI) Solutions. $29^{\text {th }}$ Annual Stanford Synchrotron Radiation Laboratory Users Meeting, October $7^{\text {th }}-8^{\text {th }}, 2002$, SLAC, Menlo Park, CA. 
Colin S. Doyle, Tom Kendelewicz, Benjamin C. Bostick, Gordon E. Brown, Jr. (2003) Soft X-ray Spectroscopic Studies of the Reaction of Cleaved Pyrite $\left(\mathrm{FeS}_{2}\right)$ Surfaces with $\mathrm{Cr}(\mathrm{VI})$ Solutions. $30^{\text {th }}$ Annual Stanford Synchrotron Radiation Laboratory Users Meeting, October $8^{\text {th }}-10^{\text {th }}, 2003$, SLAC, Menlo Park, CA.

\section{Peer-Reviewed Literature}

Colin S. Doyle, Tom Kendelewicz, Gordon E. Brown, Jr., Inhibition of the reduction of $\mathrm{Cr}(\mathrm{VI})$ at the magnetite-water interface by calcium Carbonate Coatings. Applied Surface Science (2004) in press.

doi:10.1016/j.apsusc.2004.02.035.

Colin S. Doyle, Tom Kendelewicz, Benjamin C. Bostick, and Gordon E. Brown, Jr., Soft xray spectroscopic studies of the reaction of fractured pyrite surfaces with $\mathrm{Cr}(\mathrm{VI})$-containing aqueous solutions. Geochim. Cosmochim. Acta (2004) in press.

doi:10.1016/j.gca.2004.02.015. 